\title{
Association between breakfast skipping and postprandial hyperglycaemia after lunch in healthy young individuals
}

\author{
Hitomi Ogata ${ }^{1 *}$, Yoichi Hatamoto ${ }^{2}$, Yusuke Goto ${ }^{2}$, Eri Tajiri ${ }^{3}$, Eiichi Yoshimura ${ }^{3}$, Ken Kiyono $^{4}$, \\ Yoshinari Uehara ${ }^{2}$, Kentaro Kawanaka ${ }^{2}$, Naomi Omi ${ }^{5}$ and Hiroaki Tanaka ${ }^{2} \dagger$ \\ ${ }^{1}$ Graduate School of Integrated Arts and Sciences, Hiroshima University, Higashi-Hiroshima, Hiroshima 739-8521, Japan \\ ${ }^{2}$ Faculty of Sports and Health Science, Fukuoka University, Jonan-ku, Fukuoka 814-0810, Japan \\ ${ }^{3}$ Faculty of Environmental and Symbiotic Sciences, Prefectural University of Kumamoto, Higashi-ku, Kumamoto 862-8502, \\ Japan \\ ${ }^{4}$ Graduate School of Engineering Science, Osaka University, Toyonaka, Osaka 560-8531, Japan \\ ${ }^{5}$ Faculty of Health and Sport Sciences, University of Tsukuba, Tsukuba, Ibaraki 305-8574, Japan \\ (Submitted 12 November 2018 - Final revision received 27 April 2019 - Accepted 7 May 2019)
}

\section{Abstract}

Breakfast skipping has become an increasing trend in the modern lifestyle and may play a role in obesity and type 2 diabetes. In our previous studies in healthy young individuals, a single incident of breakfast skipping increased the overall 24-h blood glucose and elevated the postprandial glycaemic response after lunch; however, it was difficult to determine whether this response was due to breakfast omission or the extra energy (i.e. lunch plus breakfast contents). The present study aimed to assess the postprandial glycaemic response and to measure their hormone levels when healthy young individuals had identical lunch and dinner, and the 24-h average blood glucose as a secondary outcome. Nine healthy young men (19-24 years) participated in two-meal trials: with breakfast (three-meal condition) or without breakfast (breakfast skipping condition). During the meals, each individual's blood glucose was continuously monitored. Skipping breakfast resulted in a significantly higher $(P<0 \cdot 001)$ glycaemic response after lunch as compared with the glycaemic response after an identical lunch when breakfast was consumed. Despite the difference in the total energy intake, the 24-h average blood glucose was similar between the two-meal conditions $(P=0 \cdot 179)$. Plasma NEFA level was significantly higher $(P<0 \cdot 05)$ after lunch when breakfast was omitted, and NEFA level positively correlated with the postprandial glycaemic response $(r 0.631, P<0.01)$. In conclusion, a single incident of breakfast skipping increases postprandial hyperglycaemia, and associated impaired insulin response, after lunch. The present study showed that skipping breakfast influences glucose regulation even in healthy young individuals.

\section{Key words: Skipping breakfast: Postprandial glycaemia: Insulin resistance: Healthy young subjects}

Over the past 50 years, breakfast has been touted as an essential part of the diet to prevent and/or treat obesity ${ }^{(1-3)}$. In fact, skipping breakfast has been associated with weight gain and other adverse health outcomes, including insulin resistance and an increased risk for developing type 2 diabetes $^{(4-9)}$. Systematic reviews, including a meta-analysis, suggested that a positive association between skipping breakfast and being overweight or obese is globally observed regardless of cultural differences among countries ${ }^{(10-13)}$. On the other hand, some reported studies do not support a clear effect of regularly consuming or skipping breakfast on body mass and energy metabolism ${ }^{(14-17)}$.

Glycaemic control is a key component of effective diabetes management because postprandial glucose level and glucose fluctuations contribute to the activation of oxidative stress. The maintenance of near-normoglycaemia is critical to minimise the risk of developing micro- and macrovascular complications that are generally associated with diabetes ${ }^{(18-21)}$, and postprandial hyperglycaemia is an independent risk factor for diabetesassociated complications and mortality ${ }^{(22)}$. Lowering glycaemia excursion and glucose variability are now considered major treatment targets in diabetic patients ${ }^{(18,23,24)}$, because postprandial hyperglycaemia was strongly associated with future development of vascular complications even when glycaemic control is restored in patients with type 2 diabetes ${ }^{(23,25,26)}$.

From the perspective of the postprandial glucose excursions, it was reported that low-carbohydrate (carbohydrate $<45 \%$ )

Abbreviations: CONGA, continuous overall net glycaemic action; DFA, detrended fluctuation analysis; $\Delta \mathrm{G}$, glucose rise to peak

* Corresponding author: Hitomi Ogata, fax +81-82-424-6589, email hogata@hiroshima-u.ac.jp

$\dagger$ Hiroaki Tanaka, one of the authors of the manuscript, deceased on 23 April 2018 
breakfast should be recommended for impaired glucose regulation subjects $^{(27)}$ and high-carbohydrate (carbohydrate $>60 \%$ ) intake at lunch provided the most favourable postprandial glucose profile than even distribution for type 2 diabetes $^{(28)}$. The effects of breakfast skipping on postprandial glucose response have been investigated in healthy middle-aged individuals (lunch contains $48 \%$ carbohydrate) $^{(29)}$ and type 2 diabetes (lunch contains $54 \%$ carbohydrate) ${ }^{(30)}$. These studies ${ }^{(29,30)}$ have shown that insulin and C-peptide peak were delayed $30 \mathrm{~min}$ after lunch on the breakfast skipping day compared with the three-meal day. Additionally, the plasma level of NEFA was significantly higher after lunch when breakfast was omitted. Therefore, these studies ${ }^{(29,30)}$ suggested that the postprandial hyperglycaemia after lunch was induced by hepatic insulin resistance and impaired insulin response. In our previous studies in healthy young individuals ${ }^{(31,32)}$, energy intake has been matched across $24 \mathrm{~h}$ following breakfast omission by increasing intake at subsequent meals (lunch and dinner). The effects of breakfast skipping elevated the postprandial glycaemic response after lunch (62\% carbohydrate) and increased the overall 24-h average blood glucose $\mathrm{e}^{(31)}$. Moreover, when breakfast skipping is done for six consecutive days, the postprandial glycaemic response only elevated after lunch ( $60 \%$ carbohydrate) on the first day of the breakfast skipping, and average blood glucose within 24 h only increased when the individual had sedentary lifestyle ${ }^{(32)}$. The concept of our studies ${ }^{(31,32)}$ was to conduct experiments with the isoenergetic diets per $\mathrm{d}$; in the breakfast skipping condition, the individual ate extra energy at lunch and dinner in order to compensate for breakfast (i.e. lunch/dinner plus breakfast contents $1 / 2$ ). Therefore, it was difficult to determine whether the high glycaemic response after lunch and increased 24-h average blood glucose for the breakfast skipping condition were consequences of breakfast omission, that is, second-meal phenomenon, or the extra energy at lunch.

The purpose of the present study was to assess the postprandial glycaemic response and to measure insulin, C-peptide and NEFA levels when healthy young individuals had identical lunch and dinner, and the 24-h average blood glucose as a secondary outcome. Thus, the present study aimed to clarify the influence of breakfast skipping on dynamics of blood glucose and hormone in healthy young individuals.

\section{Methods}

\section{Subjects}

A total of nine male sedentary individuals participated in the present study; these individuals were recruited through a poster on the laboratory information board. Their age, height and body weight were 21.4 (SD 1.4) years, 175.1 (SD 5.4) $\mathrm{cm}$ and 73.3 (sD 16.2) kg, respectively. According to the WHO criteria ${ }^{(33)}$, one individual was overweight and one was obese. Individuals with food allergies, who are occasional or habitual breakfast skippers, who perform regular exercise (more than three times per week), who smoke, with chronic diseases (diabetes, hypertension and hyperlipidaemia) or who regularly use medications were excluded. The present study was conducted according to the guidelines laid down in the Declaration of Helsinki, and all
Table 1. Energy intake and nutrients for three standardised meals on the experiment day (Mean values and standard deviations)

\begin{tabular}{|c|c|c|c|c|c|c|}
\hline & \multicolumn{2}{|c|}{ Breakfast } & \multicolumn{2}{|c|}{ Lunch } & \multicolumn{2}{|c|}{ Dinner } \\
\hline & Mean & SD & Mean & SD & Mean & SD \\
\hline Energy intake $(\mathrm{kcal} / \mathrm{d})^{*}$ & $861 \cdot 7$ & $187 \cdot 0$ & $859 \cdot 8$ & 189.2 & $859 \cdot 3$ & 193.5 \\
\hline \multicolumn{7}{|l|}{ Macronutrients (g) } \\
\hline Protein & $32 \cdot 8$ & $7 \cdot 1$ & 31.9 & 6.9 & $32 \cdot 0$ & 7.5 \\
\hline Fat & $24 \cdot 3$ & 4.9 & $23 \cdot 6$ & $5 \cdot 0$ & 23.6 & 5.8 \\
\hline Carbohydrate & $127 \cdot 8$ & 28.7 & $129 \cdot 9$ & 29.4 & $129 \cdot 8$ & $28 \cdot 2$ \\
\hline \multicolumn{7}{|l|}{ Macronutrients (\%) } \\
\hline Protein & $15 \cdot 2$ & 0.4 & 14.9 & 0.4 & 14.9 & 0.5 \\
\hline Fat & 25.5 & 0.8 & $24 \cdot 7$ & 0.7 & $24 \cdot 6$ & 0.7 \\
\hline Carbohydrate & $59 \cdot 3$ & 0.7 & $60 \cdot 4$ & 0.9 & 60.5 & 0.9 \\
\hline
\end{tabular}

* To convert energy in kcal/d to $\mathrm{kJ} / \mathrm{d}$, multiply by 4.184 .

procedures involving human subjects were approved by the Local Ethics Committee of Hiroshima University, Japan (reference no.: 29-55). The experimental procedures and possible risks were fully explained to the participants before they signed the written informed consent.

Based on our previous study ${ }^{(31)}$, power analysis revealed that a sample size of eight individuals is required to provide $80 \%$ power to detect $5 \%$ difference between two dietary conditions in the 24-h average blood glucose. Because the 24-h average glucose value was highly related with the postprandial glycaemic response ${ }^{(34)}$, and there were no previous data about the difference of acute postprandial glycaemia which were available for the sample size calculation for our study design. To allow discontinuation or measurement errors during the meal intervention, nine individuals were recruited.

\section{Study design}

The present study was a randomised crossover design with the following two experimental conditions: with breakfast (i.e. three-meal condition) and without breakfast (i.e. breakfast skipping condition). The two trials were conducted 1 week apart.

At $1 \mathrm{~d}$ prior to each trial, the participants were instructed to refrain from rigorous physical activity and from consuming beverage containing energy, caffeine or alcohol. The energy intake was controlled by individually adjusting three meals prior to each trial, and the size of the standardised meal during each trial was individually adjusted (2579 (sD 569) kcal/d (10 791 (sD 2381) $\mathrm{kJ} / \mathrm{d}$ ), $15 \%$ protein, $25 \%$ fat and $60 \%$ carbohydrates; Table 1), based on the estimated energy requirement assuming a physical activity factor at $1 \cdot 50^{(35,36)}$. Note that the size of the standardised meal was provided for each individual combining the following: pre-packed food or canned food; rice as a staple diet; beef, fish, bean and curry as main dishes; miso soup, seaweed, bamboo shoot and Japanese radish as side dishes; cheese as a dairy product; and vegetable juice as a fruit.

The participants came to the laboratory using a taxi to avoid the influence of physical activity on the experiment. During the experimental trials, the participants received breakfast at 08.30 hours $(33.3 \%$ of daily energy intake) or no breakfast (0 kcal $(0 \mathrm{~kJ}))$, lunch at 13.30 hours $(33.3 \%$ of daily energy intake) and dinner at 18.30 hours (33.3\% of daily energy intake); they 
were also instructed to sit on the chair except when going to the toilet, and they spent the whole time watching television or personal computers and reading books. When breakfast was skipped (i.e. breakfast skipping condition), the participants ate identical lunch and dinner as the three-meal condition; that is, the energy intake per $\mathrm{d}$ decreased to $2 / 3$ compared with the three-meal condition (1717 (sD 381) kcal/d (7184 (sD 1594) kJ), $15 \%$ protein, $25 \%$ fat and $60 \%$ carbohydrates).

\section{Measurements}

Continuous glucose monitoring. The glucose levels were continuously measured using a glucose monitor (iPro2; Medtronic MiniMed) connected to a glucose sensor (Enlite Glucose Sensor, Medtronic MiniMed). The mean absolute relative difference value of this device is $11 \%{ }^{(37)}$. The sensor was placed on each participant's abdomen $1 \mathrm{~d}$ before the experiment. The participants were asked to record their blood glucose concentrations more than four times by a finger stick the day before the experiment for calibration purposes.

The blood glucose within $24 \mathrm{~h}$ was used from 08.00 hours at meal intervention day to 08.00 hours the next morning. Postprandial blood glucose response was calculated as an AUC of the blood glucose curve above average 15-min pre-meal levels within $4 \mathrm{~h}$ using the trapezoidal method. The glycaemic variability was evaluated using the flowing approaches:

(a) Mean amplitude of glycaemic excursion is defined as the average glycaemic excursions exceeding $1 \mathrm{sD}^{(38)}$.

Continuous overall net glycaemic action (CONGA $n$ ) is defined as the SD of all the differences between the current observation and the observation at $n$ hours (1, 2 and $4 \mathrm{~h}$ before the observation) ${ }^{(39)}$. For instance, for $n 1$, the calculations would begin as follows: blood glucose at 09.00 hours minus blood glucose at 08.00 hours, blood glucose at 09.05 hours minus blood glucose at 08.05 hours, blood glucose at 09.10 hours minus blood glucose at 08.10 hours and so on until blood glucose 08.00 hours (the next day) minus blood glucose at 07.00 hours. Then, the SD of the summed differences between these data was calculated. CONGA $n$ is similar to SD but assesses glucose variability within a predetermined time window.

(b) Mean indices of meal excursions is defined as glucose rise to peak $(\Delta G)$, time to peak $(\Delta T)$ and timeliness of recovery to baseline glycaemia (\% baseline) ${ }^{(40)}$.

(c) Detrended fluctuation analysis (DFA), which accurately quantifies the temporal correlation property of time series data $^{(41)}$, has been previously described in detail ${ }^{(42)}$. In DFA, long-range correlation is characterised by the exponent $\alpha$ in the scaling (power-law) relation $F(n)-n^{\alpha}$, where $F(n)$ is a square root of mean-square deviations around a polynomial trend averaged over segments with length $n$ of integrated time series. In DFA, $n$ represents the analysed window size in min, while $F(n)$ is referred as the fluctuation function. In the present study, we used the glucose data measured every $5 \mathrm{~min}$, and we calculated $F(n)$ over the range $40 \leq n \leq 350 \mathrm{~min}$ (in the logarithmic scale, $\left.1.602 \leq \log _{10} n \leq 2.544\right)$ and estimated the crossover of its scaling behaviour using linear least squares fitting. Finally, the short-range scaling exponent $\left(\alpha_{1}\right)$ was shorter than the crossover point, and the long-range scaling exponent $\left(\alpha_{2}\right)$ was longer than the crossover point. Additionally, we calculated the mean values of $\log _{10} F(n)$ at each scale in every participant, which was denoted by $\log _{10} F m(n)$. White noise (uncorrelated time series) is characterised by $\alpha=0.5$, while Brownian motion (integrated white noise) is characterised by $\alpha=1 \cdot 5$. Similar to the relation between white noise and Brownian motion, the value of $\alpha$ after the integration is increased by 1 . Therefore, a negatively correlated long-range fluctuation of increments is represented by $1<\alpha<1.5$ for the measured glucose time series, whereas a positively correlated increments is represented by $1.5<\alpha<2.0$; furthermore, $\alpha>2.0$ can be explained by the repeated integration.

\section{Biochemical and hormonal blood analyses}

Following an overnight fast, the participants visited the test site laboratory at 08.00 hours in the morning and rested before the first blood collection. A baseline blood sample was subsequently obtained. Blood samples $(2.5 \mathrm{ml})$ were also collected at 0,60 and 120 min after each meal sessions; blood was obtained at the same time even after skipping breakfast. Serum and plasma samples were obtained after a 15 -min centrifugation at $4^{\circ} \mathrm{C}$, and the samples were stored at $-80^{\circ} \mathrm{C}$ until analysis. From the obtained blood samples, blood glucose, serum insulin, C-peptide and plasma NEFA levels were measured. All the analyses were conducted using LSI Medience according to the operation manual.

\section{Physical activity}

Physical activity was measured using a tri-axial accelerometer (JHA- $75^{\circ} \mathrm{C}$; Omron Healthcare) $)^{(43)}$. The participants wore the accelerometer on their waist during the intervention period. Physical activity was assessed using step counts.

\section{Subjective appetite and feeling}

The participants' subjective appetite (hunger and fullness) and feelings (fatigue and concentration) were evaluated using visual analogue scales. These scales were completed pre-breakfast (08.30 hours) and post-breakfast (09.30 and 10.30 hours), prelunch (13.30 hours) and post-lunch (14.30 and 15.30 hours) and pre-dinner (18.30 hours) and post-dinner (19.30 and 20.30 hours). Hunger, fullness, exhaustion and concentration were rated on a $100-\mathrm{mm}$ line preceded by the question 'How hungry do you feel right now?' and anchored by 'not at all hungry' on the left and 'extremely hungry' on the right. Fullness, fatigue and concentration were rated using a visual analogue scales with the question 'How full/fatigue/concentration do you feel right now?', with the anchors 'no at all' and 'extremely'.

\section{Statistical analysis}

Data are presented as mean values and standard deviations. Differences in the 24-h average blood glucose, standard deviation, glycaemic variability (mean amplitude of glycaemic 
excursion, CONGA $n$ and mean indices of meal excursions) and DFA indices $\left(\alpha_{1}, \alpha_{2}\right.$ and $\left.F m\right)$ and postprandial blood glucose response (lunch and dinner) between the three-meal and breakfast skipping conditions were analysed using the paired $t$ test. The differences between the DFA scaling exponents $\left(\alpha_{1}\right.$ and $\alpha_{2}$ ) and the uncorrelated 'reference' value of $\alpha=1.5$ were also evaluated using the paired $t$ test. Physical activity level from 08.00 to 21.00 hours between the three-meal and breakfast skipping conditions was analysed using the paired $t$ test. To evaluate the differences in blood glucose between the two-meal conditions, mean values in the morning (08.00-13.30 hours), afternoon (13.30-18.30 hours), evening (18.30-23.30 hours) and sleep (23.30-08.00 hours) were calculated for each participant, and repeated measures of two-way ANOVA followed by a post hoc Bonferroni test were used. To evaluate the differences in insulin, C-peptide, NEFA and visual analogue scales scores between the two-meal conditions and repeated measures of two-way ANOVA followed by a post hoc Bonferroni test were used. All statistical analyses were performed using SPSS version 22.0 (SPSS Japan Inc.). Differences were considered significant when the error probability was $<0 \cdot 05$.

\section{Results \\ Blood glucose}

The level of HbA1c was $5 \cdot 2$ (SD 0.3) \% (range $4 \cdot 8-5 \cdot 7 \%$ ), and all the participants were healthy. Note that only one individual had an HbA1c level of $5.7 \%$. However, of the eighteen samples at the fasting plasma glucose (i.e. two conditions per individual), two were found to have normal high glucose: one was $110 \mathrm{mg} / \mathrm{dl}$ $(6 \cdot 1 \mathrm{mmol} / \mathrm{l})$ and the other was $114 \mathrm{mg} / \mathrm{dl}(6.3 \mathrm{mmol} / \mathrm{l})$. (To convert glucose in $\mathrm{mg} / \mathrm{dl}$ to $\mathrm{mmol} / \mathrm{l}$, multiply by 0.0555 .)

Differences in the mean blood glucose between the twomeal conditions in the morning (08.00-13.30 hours) (109.3 $(\mathrm{SD} 25.4) \mathrm{mg} / \mathrm{dl}$ for the three-meal condition $v$. 104.9 (sD 16.5$) \mathrm{mg} / \mathrm{dl}$ for the breakfast skipping condition, $P=0.536$ ), evening (18.30-23.30 hours) (116.9 (SD 23.6) $v . \quad 119.4$ (sD 18.9$) \mathrm{mg} / \mathrm{dl}, P=0.480)$ and during sleep (23.30-08.00 hours) (97.3 (sD 15.2) v. 102.9 (sD 31.3) $\mathrm{mg} / \mathrm{dl}, P=0.432$ ) were not significant; however, there was significant difference in the blood glucose in the afternoon (13.30-18.30 hours) (109.7 (SD 23.6) $v$. $130 \cdot 4$ (sD 22.3) mg/dl, $P<0 \cdot 05$ ) (Fig. 1(a)).

After lunch, the postprandial blood glucose AUC in the breakfast skipping condition was significantly higher than that of the three-meal condition (3207 (sD 2476) v. 5762 (sD 2585) $\mathrm{mg} / \mathrm{dl} \times$ $4 \mathrm{~h}, P<0 \cdot 01$ ), although there was no significant difference after dinner between these conditions (4092 (sD 3063) $v .4743$ (sD 3636) $\mathrm{mg} / \mathrm{dl} \times 4 \mathrm{~h}, P=0.537$ ) (Table 2). Breakfast skipping did not significantly affect the 24 -h average blood glucose values, CONGA1 and mean indices of meal excursions for dinner ( $P=0.179, P=0.145, P=0.941, P=0.800$ and $P=0.079$, respectively). Meanwhile, the 24-h sD (16.9 (sD 9.4) 21.6 (sD 10.6)), mean amplitude of glycaemic excursion (51.5 (sD 9.8) $v \cdot 66.5$ (sD 10.2)), CONGA2 (1.27 (sD 0.81) v. 1.78(sD 1.02)), CONGA4 (1.42 (SD 0.85) $v .2 \cdot 11$ (SD 1.22)) and mean indices of meal excursions for lunch $(\Delta \mathrm{G}: 41 \cdot 3(\mathrm{sD} 21.5) v .81 \cdot 1(\mathrm{sD} 30 \cdot 4),-\Delta \mathrm{G} / \Delta \mathrm{G}: 85.9(\mathrm{sD} 11 \cdot 6) v .73 .7$
(sD 8.4)) were significantly different between the three-meal and breakfast skipping conditions $(P<0.05$, Table 2$)$.

The DFA plots for the three-meal condition (Fig. 2(a)) and for the skipping breakfast condition (Fig. 2(b)) are shown in Fig. 2. The two-line regression placed a crossover point for the grouped data at approximately $130 \mathrm{~min}$, and the individual crossover points fell in a range from $110 \cdot 0$ to $197.5 \mathrm{~min}$ on the three-meal condition and from 82.5 to $152.5 \mathrm{~min}$ on the skipping breakfast condition. In the short-range regimen ( $<130 \mathrm{~min}$ for these conditions), the scaling exponent $\left(\alpha_{1}\right)$ for the three-meal condition was 2.95 (SD 0.19), and for the skipping breakfast condition, it was 3.02 (sD $0 \cdot 12$ ). These $\alpha_{1}$ scaling exponents were larger than the 'uncorrelated reference value' of $\alpha=1.5$ ( $P<0.001)$, meaning that the glucose fluctuation short-range regimen was positively correlated; that is, the net effects of glucose flux/reflux persisted within these shorter time scales. In the long-range regimen, the scaling exponent $\left(\alpha_{2}\right)$ for the three-meal condition was 1.57 (SD 0.18) and that for the skipping breakfast condition was $1 \cdot 84$ (sD 0.44). Moreover, the scaling exponent for the skipping breakfast condition was significantly different from $1.50(P<$ 0.05), but the scaling exponent for the three-meal condition was not significantly different from $1.50(P=0 \cdot 717)$. Between the two-meal conditions, there was no significant difference in Fm (Table 2).

\section{Biochemical and hormonal markers}

Compared with the three-meal condition, insulin and C-peptide levels in the morning were significantly lower, and insulin and C-peptide levels after lunch were significantly higher on the breakfast skipping condition: insulin at 09.30 hours (82.7 (SD 44.3) $v$. 6.7 (sD 4.2 ) $\mu \mathrm{U} / \mathrm{ml}, P<0.001$ ), insulin at 10.30 hours $(42.7$ (sD 35.3) v. $6.9(\mathrm{sD} 5.0) \mu \mathrm{U} / \mathrm{ml}, P<0.01)$, insulin at 15.30 hours (48.1 (sD 55.8) v. 66.5 (sD 58.0) $\mu \mathrm{U} / \mathrm{ml}, P<0.05$ ), C-peptide at 09.30 hours $(8.6(\mathrm{sD} 3.2) v .1 .5(\mathrm{sD} 0.9) \mathrm{ng} / \mathrm{ml}, P<0.001)$, C-peptide at 10.30 hours $(6.2(\mathrm{sD} \mathrm{3.8)} v .1 .4$ (sD 0.9) ng/ml, $P<0.01$ ), C-peptide at 13.30 hours (2.6 (sD 2.3) v. $1.2(\mathrm{sD} 0 \cdot 8) \mathrm{ng} / \mathrm{ml}$, $P<0.05$ ), C-peptide at 14.30 hours (7.5 (sD 2.9) $v .8 .9$ (sD 2.0$) \mathrm{ng} / \mathrm{ml}, P<0.005$ ) and C-peptide at 15.30 hours (6.5 (sD 3.8) v. 9.3 (sD 3.4) ng/ml, $P<0.001$ ). The NEFA level in the morning and after lunch in the breakfast skipping condition was significantly higher than that of the three-meal condition: at 09.30 hours $(0.20$ (sD 0.08) v. 0.58 (sD 0.24) mEq/1, $P<0.001$ ), at 10.30 hours $(0.18$ (sD 0.08$) \quad v .0 .59 \quad(\mathrm{sD} \quad 0.30) \quad \mathrm{mEq} / \mathrm{l}$, $P<0.01$ ), at 13.30 hours (0.29 (sD 0.13) v. 0.65 (sD 0.24) mEq/l, $P<0.001)$ and at 14.30 hours $(0.19$ (SD 0.11$) \quad v .0 .26$ (sD 0.17$) \mathrm{mEq} / \mathrm{l}, P<0.05$ ). However, these results were not observed after dinner (Fig. 1(b)-(d)).

NEFA levels pre-lunch time (13.30 hours) were positively correlated with the rise in blood glucose after lunch, that is, the maximum glucose after lunch minus the average 15-min prelunch glucose levels $(r 0.631, P<0 \cdot 01$, Fig. 1(e)).

\section{Physical activity}

The participants' step counts in the three-meal and breakfast skipping conditions were 547 (SD 266) and 534 (SD 258) counts, respectively $(P=0 \cdot 890)$. 

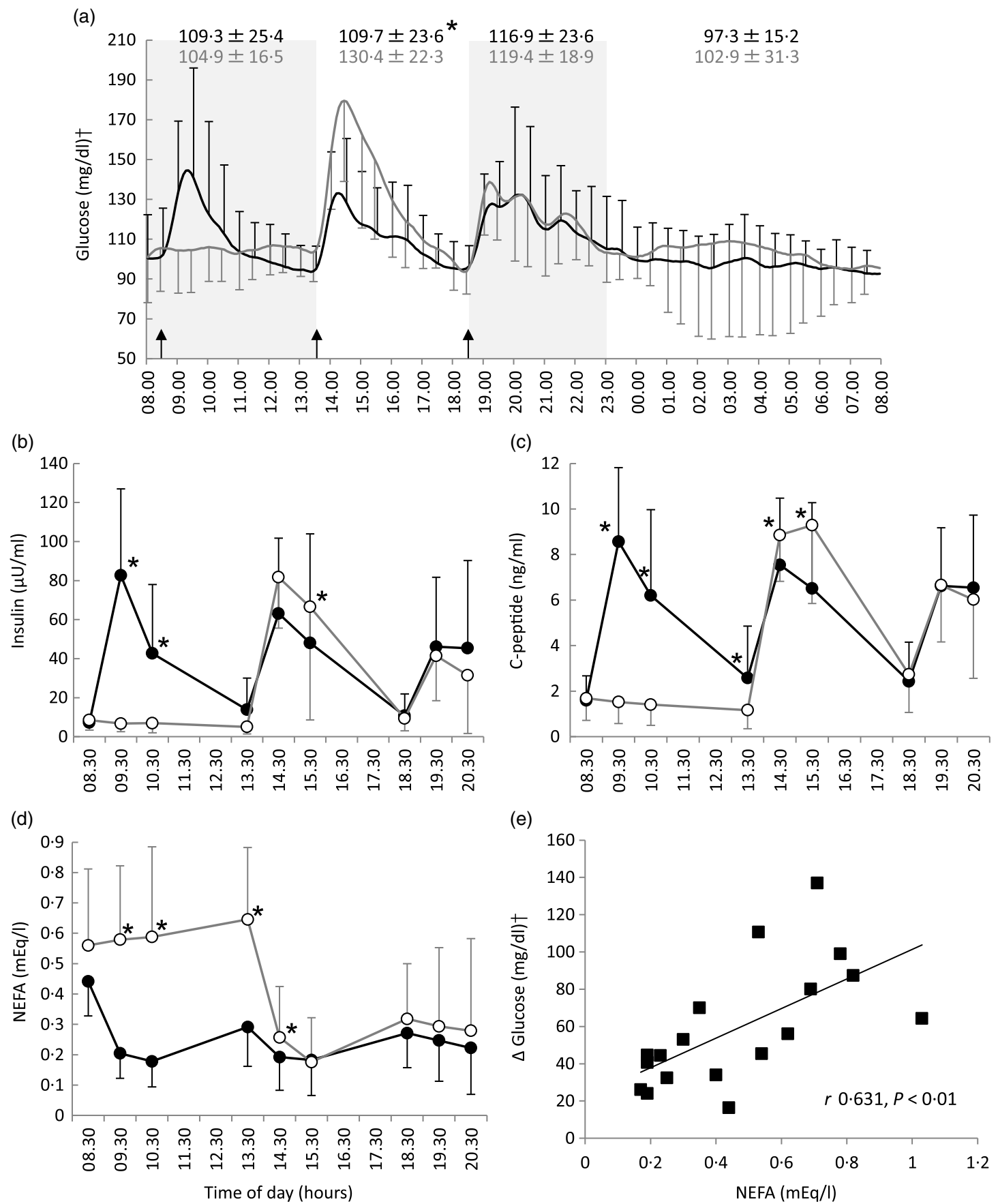

Fig. 1. All-day graphs for (a) glucose, (b) insulin, (c) C-peptide and (d) NEFA. Values are means, with standard deviations represented by vertical bars. (e) Relationship between pre-lunch NEFA and the maximal increase in blood glucose level after lunch. Mean values of blood glucose for all participants $(n 9)$ were plotted every 5 min; + SD for three meals and -SD for breakfast skipping conditions were plotted every $30 \mathrm{~min}$. Mean values of insulin, C-peptide and NEFA were plotted every $60 \mathrm{~min} ;+$ SD for three meals and -SD for breakfast skipping conditions were also plotted every $60 \mathrm{~min}$. ${ }^{*}$ Significant difference between trials at the annotated time point $(P<0.05)$. $\bullet$, Eating breakfast; $\odot$, skipping breakfast. † To convert glucose in $\mathrm{mg} / \mathrm{dl}$ to $\mathrm{mmol} / \mathrm{l}$, multiply by 0.0555 .

\section{Rating of appetites and feelings}

Ratings of hunger (Fig. 3(a)), fullness (Fig. 3(b)), fatigue (Fig. 3(c)) and concentration (Fig. 3(d)) are shown in Fig. 3. Rating scores for hunger in breakfast skipping condition were significantly higher than those in the three-meal condition (09.30 and 10.30 hours). Additionally, rating scores for fullness in the three-meal condition were significantly higher than those in the breakfast skipping condition (09.30 and 10.30 hours). These subjective appetites showed to be slightly different at pre-lunch (13.30 hours). On the contrary, rating scores for fatigue and concentration showed a slight difference between the two conditions (fatigue, 14.30 hours; concentration, 08.30 and 09.30 hours). 
Table 2. Indices of glycaemic variability for three-meal condition and skipping breakfast condition*

(Mean values and standard deviations)

\begin{tabular}{|c|c|c|c|c|c|}
\hline \multirow[b]{2}{*}{ Condition } & \multicolumn{2}{|c|}{ Three-meal } & \multicolumn{2}{|c|}{$\begin{array}{l}\text { Breakfast } \\
\text { skipping }\end{array}$} & \multirow[b]{2}{*}{$P$} \\
\hline & Mean & SD & Mean & SD & \\
\hline \multicolumn{6}{|c|}{ Postprandial blood glucose response of $4 \mathrm{~h}(\mathrm{mg} / \mathrm{dl}) \dagger$} \\
\hline Lunch & 3207 & 2476 & 5762 & 2585 & 0.001 \\
\hline Dinner & 4092 & 3063 & 4743 & 3636 & 0.537 \\
\hline \multicolumn{6}{|c|}{ Blood glucose within $24 \mathrm{~h}$} \\
\hline Average (mg/dl) & $106 \cdot 7$ & $18 \cdot 8$ & $112 \cdot 5$ & $22 \cdot 3$ & 0.179 \\
\hline SD & $16 \cdot 9$ & 9.4 & $21 \cdot 6$ & $10 \cdot 6$ & 0.045 \\
\hline MAGE & 51.5 & 9.8 & 66.5 & $10 \cdot 2$ & 0.019 \\
\hline \multicolumn{6}{|l|}{ CONGA $n$} \\
\hline CONGA1 & 1.04 & 0.63 & 1.24 & 0.57 & 0.145 \\
\hline CONGA2 & 1.27 & 0.81 & 1.78 & 1.02 & 0.016 \\
\hline CONGA4 & 1.42 & 0.85 & $2 \cdot 11$ & 1.22 & 0.013 \\
\hline \multicolumn{6}{|l|}{ MIME of lunch } \\
\hline$\Delta \mathrm{G}(\mathrm{mg} / \mathrm{dl})$ & $41 \cdot 3$ & 21.5 & $81 \cdot 1$ & $30 \cdot 4$ & 0.001 \\
\hline$\Delta \mathrm{T}(\min )$ & $57 \cdot 2$ & $40 \cdot 3$ & $56 \cdot 1$ & $14 \cdot 1$ & 0.924 \\
\hline$-\Delta \mathrm{G} / \Delta \mathrm{G}(\%)$ & 85.9 & 11.6 & $73 \cdot 7$ & 8.4 & 0.003 \\
\hline \multicolumn{6}{|l|}{ MIME of dinner } \\
\hline$\Delta \mathrm{G}(\mathrm{mg} / \mathrm{dl})$ & $51 \cdot 3$ & $36 \cdot 5$ & $50 \cdot 8$ & 33.0 & 0.941 \\
\hline$\Delta \mathrm{T}(\min )$ & 94.4 & $82 \cdot 1$ & 83.3 & $77 \cdot 2$ & 0.800 \\
\hline$-\Delta G / \Delta G(\%)$ & $82 \cdot 1$ & 11.4 & 73.7 & $8 \cdot 4$ & 0.079 \\
\hline \multicolumn{6}{|l|}{ DFA } \\
\hline$\alpha_{1}$ (short range) & 2.95 & 0.19 & 3.02 & 0.12 & 0.073 \\
\hline$\alpha_{2}$ (long range) & 1.57 & 0.18 & 1.84 & 0.44 & 0.047 \\
\hline$F m$ & 0.66 & 0.18 & 0.73 & 0.16 & 0.238 \\
\hline
\end{tabular}

MAGE, mean amplitude of glycaemic excursion; CONGAn, continuous overall net glycaemic action - the SD of all the differences, after the first $n$ hours, between the current observation and the observation $n$ hours (1,2 and $4 \mathrm{~h}$ before the observation); MIME, meal indices of meal excursions; $\Delta G$, postprandial glucose rise to peak; $\Delta T$, time to

peak; $-\Delta \mathrm{G} / \Delta \mathrm{G}$, baseline recovery $1 \mathrm{~h}$ after peak; DFA, detrended fluctuation analysis. * To convert glucose in $\mathrm{mg} / \mathrm{dl}$ to $\mathrm{mmol} / \mathrm{l}$, multiply by 0.0555 .

$\dagger$ Postprandial blood glucose response within $4 \mathrm{~h}$ was calculated as an AUC of the blood glucose curve above average 15 -min pre-meal levels during $4 \mathrm{~h}$ using the trapezoidal method.

\section{Discussion}

In the present study, we conducted an experiment to clarify the influence of breakfast skipping on the dynamics of blood glucose and hormone responses in healthy young individuals. All the meal including the breakfast consisted of a normal Japanese standardised meal (15\% of energy from protein, $25 \%$ from fat and $60 \%$ from carbohydrate). As a result, the omission of breakfast resulted in a significantly higher glycaemic response only after lunch as compared with the glycaemic response after an identical lunch when breakfast was consumed. Interestingly, despite the difference in the total energy intake (breakfast skipping condition was $33 \%$ decreased), the 24-h average blood glucose was similar between the two-meal conditions. Furthermore, plasma NEFA level was significantly higher after lunch when breakfast was omitted, and the level of NEFA positively correlated with the postprandial glycaemic response.

The result of the hyperglycaemic response after lunch showed the 'second-meal phenomenon' in the present study, and it is consistent with the previous studies ${ }^{(29,44,45)}$. The second-meal phenomenon has been observed consistently in healthy people $\mathrm{e}^{(29,44,45)}$, but its presence is controversial in people with diabetes mellitus ${ }^{(18,23,24,46-48)}$. The second-meal phenomenon can influence the postprandial glycaemic response at the next meal: meal skipping ${ }^{(29,30,47,49,50)}$, fermentable dietary fibre consumption $^{(51-54)}$, fibre-enriched bread consumption ${ }^{(55)}$, low glycaemic-index meal consumption ${ }^{(56-63)}$, high-protein meal consumption $^{(64-66)}$ or high-fat meal consumption ${ }^{(67)}$. Moreover, the extent of postprandial rise in plasma glucose depends not only on the quantity and nature of food ingested but also on the metabolic state, that is, increased muscle glycogen storage $^{(29,46,47,64,68)}$, decreased hepatic insulin clearance ${ }^{(45)}$, slowed gastric emptying ${ }^{(61,62)}$, increased incretion hormone secretion and stronger glucose potentiation and suppression of endogenous glucose production ${ }^{(63)}$, immediately prior to eating.

We investigated the possible role of NEFA level, because suppression of NEFA after the first meal has been suggested as an important mechanism for the second-meal phenomenon. Due to omission of breakfast, plasma NEFA level was significantly higher in the morning, that is, acute elevation of plasma NEFA induced hepatic insulin resistance and increased hepatic glucose production in healthy individuals ${ }^{(69,70)}$. The NEFA level just before lunch correlated positively with the post-lunch glucose increment, a finding that is consistent with the previous reports showing similar results in both diabetic and nondiabetic people $29,46,47,49,64,68)$. Therefore, skipping breakfast triggers hepatic insulin resistance and increased hepatic glucose production; consequently, glucose level elevated the postprandial glycaemic response after lunch. Wolever et al. ${ }^{(68)}$ showed that the acute role of NEFA on insulin action has been demonstrated in a study where the different compositions of the first meals resulted in different patterns of NEFA responses prior to the second meal. The lesser rebound of plasma NEFA resulting in lower concentrations before lunch was also closely related to the improved glycaemic responses after lunch in nondiabetic subjects. Jovanovic et al. ${ }^{(29)}$ showed a negative relationship between the increment in muscle glycogen signal and pre-lunch NEFA level and hypothesised that suppressed NEFA level after the first meal improves insulin action, which would facilitate postprandial muscle glycogen storage. The authors also showed that the NEFA levels before lunch correlated positively with the post-lunch increase in blood glucose ${ }^{(29)}$. The present study is different from the present study based on the following points: (1) identical meals were provided, not according to the individual's body weight, (2) glucose levels were measured only up to $4 \mathrm{~h}$ after lunch and (3) the authors did not mention the average blood glucose levels within $24 \mathrm{~h}$. By contrast, Jakubowicz et al. ${ }^{(30)}$ showed that breakfast skipping in patients with type 2 diabetes induced higher glucose excursions after lunch and dinner, and plasma NEFA levels were significantly increased throughout the day. Thus, skipping breakfast increases postprandial hyperglycaemia after lunch and dinner in association with impaired insulin response, despite eating the same amount of energy for lunch and dinner ${ }^{(30)}$. The effect of second-meal phenomenon was not only restricted to the subsequent meal but also extended to dinner in patients with type 2 diabetes; that is, it had a much longer duration than previously anticipated. In fact, omission of breakfast indeed worsened the postprandial glucose and impaired insulin secretion, as reflected by both delayed insulin peak and decreased insulin response at lunch and dinner ${ }^{(30)}$. Furthermore, the increased postprandial hyperglycaemia after lunch and dinner was not caused by the meal energy in patients with type 2 diabetes. 
(a)

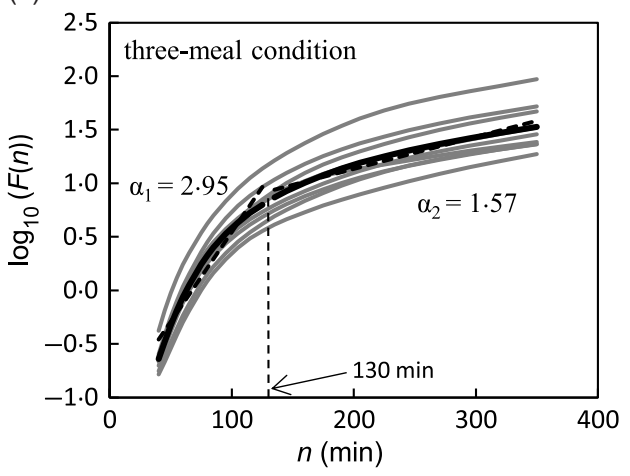

(b)

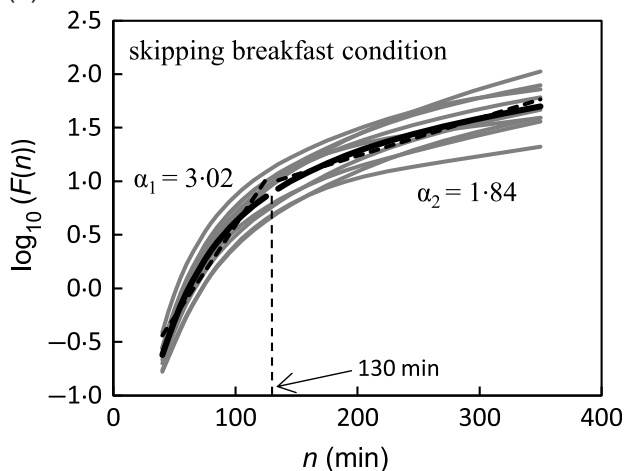

Fig. 2. Trial fluctuation functions $F(n)$ for three-meal (a) and breakfast skipping conditions (b) ( $n 9)$. The black lines show the data for the mean value of each condition, and the grey lines show the data of each participant.

(a)

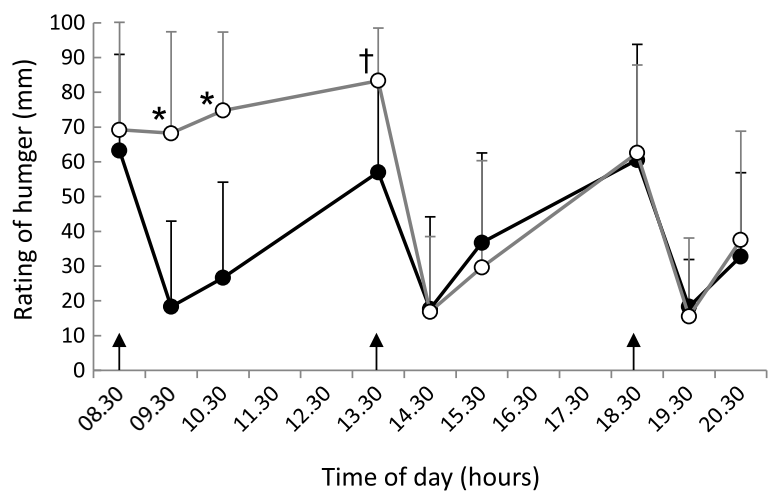

(c)

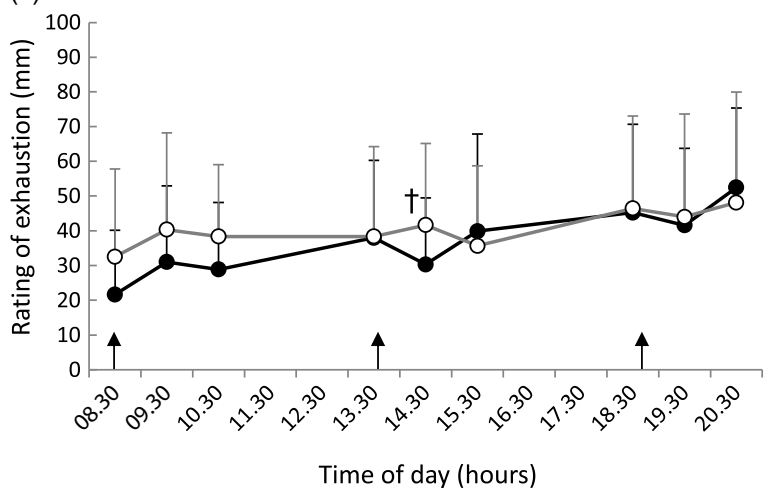

(b)

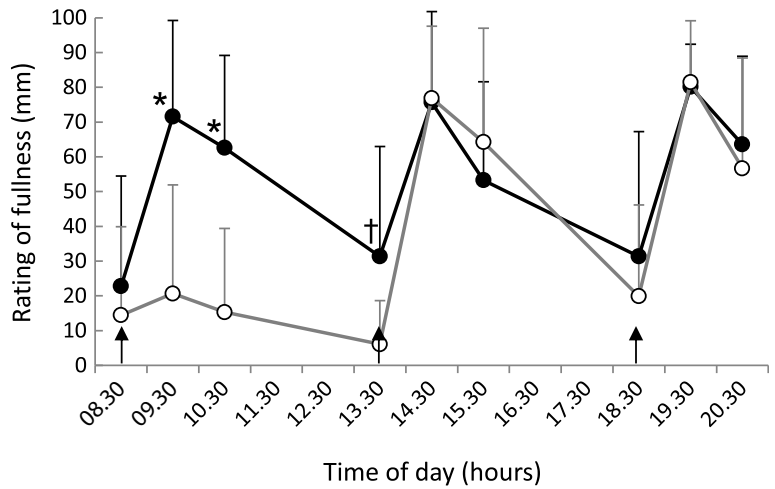

(d)

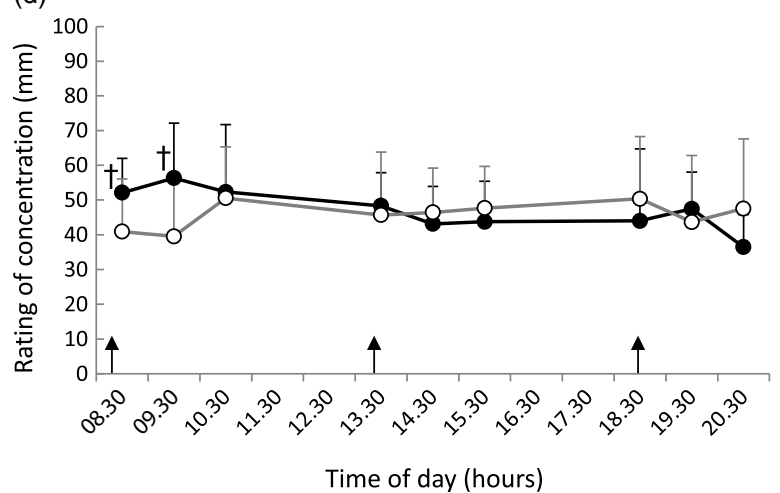

Fig. 3. Ratings of (a) hunger, (b) fullness, (c) exhaustion and (d) concentration throughout the day. Data are plotted every 60 min. Values are means, with standard deviations represented by vertical bars. ${ }^{*}$ Significant difference between trials at the annotated time point $(P<0.05)$. $† P<0.1$. $\bullet$, Eating breakfast; $\circ$, skipping breakfast.

The 24-h average blood glucose was not different between the two-meal conditions, with the following possible mechanisms: (1) because insulin and C-peptide levels for the threemeal condition were significantly higher compared with that of breakfast skipping condition, (2) because second-meal phenomenon was induced in the breakfast skipping condition and (3) because humans have glucose homeostasis. In the present study, the healthy individuals ate breakfast that has even distribution (33\% of total energy and $60 \%$ carbohydrate); consequently, the postprandial glycaemic response after lunch was significantly increased in the breakfast skipping condition, which is consistent with the previous studies ${ }^{(29,44)}$. Previous study that considered the amount of carbohydrate ingested at breakfast, although it is not a breakfast omission trial, reported the following: for type 2 diabetes, it was reported that big breakfast (33\% of total energy and 37-48\% carbohydrate) improved glycaemic control than small breakfast (12.5\% of total energy and 60-70\% carbohydrate) ${ }^{(71)}$, and high-carbohydrate 
(carbohydrate $>60 \%$ ) intake at lunch provided the most favourable postprandial glucose profile than even distribution ${ }^{(28)}$. For impaired glucose regulation subjects, it was reported that low-carbohydrate (carbohydrate $<45 \%$ ) breakfast improved glycaemic control $^{(27)}$.

Our previous studies ${ }^{(31,32)}$, which used a metabolic chamber, were conducted with the same energy intake (as to our present study) per $d$ to measure the energy expenditure; in the breakfast skipping condition, the individual ate extra energy at lunch and dinner in order to compensate for breakfast. Consequently, the overall 24-h average blood glucose and glycaemic response increased when the breakfast was omitted and stayed under the indirect calorimetry ${ }^{(31,32)}$. In the present study, breakfast skipping resulted in hyperglycaemic response after lunch even if participants consumed the same amount of energy. However, despite the difference in the total energy intake, the 24-h average blood glucose was similar between the two-meal conditions. Thus, it was suggested that reducing the number of meal (i.e. at least breakfast skipping) has a negative effect on glucose metabolism even in healthy young individuals. Taken together, the result of the hyperglycaemic response after lunch was due to the breakfast skipping, and the increased 24-h average blood glucose was also due to the second-meal phenomenon. The present study showed that there was no significant difference in the fasting blood glucose level the day after the meal intervention day between the two conditions. The postprandial hyperglycaemia is a more sensitive early symptom of diabetes than fasting blood glucose $\mathrm{e}^{(72)}$. Moreover, postprandial hyperglycaemia is a risk factor that is different from fasting hyperglycaemia, and it increases the risk of mortality ${ }^{(73-76)}$. The results of the present study, therefore, suggest that breakfast skipping increases the risk of lifestyle-related diseases in healthy individuals.

The dietary behaviours, such as skipping breakfast, what to eat for breakfast, how much to eat during breakfast and the macronutrient composition of breakfast, receive an increasing attention worldwide because of their significant physical, mental and cognitive effects during childhood and adolescence ${ }^{(77,78)}$. In the present study, fatigue was slightly higher in the afternoon in the skipping breakfast condition than that in the three-meal condition. This finding suggested that a sudden increase in blood glucose level may have an influence on mentality. With regard to the rating of concentration, it was slightly lower in the skipping condition in the morning than that in the three-meal condition. This finding suggested that the omission of breakfast caused a decrease in concentration. Therefore, breakfast is important in improving not only physical performance but also mental performance.

The limitations of the present study were as follows: the sample size was small and the age of the subjects was limited.

In conclusion, a single incident of breakfast skipping increases postprandial hyperglycaemia after lunch in association with impaired insulin response in healthy young individuals. The present study shows that skipping breakfast influences glucose regulation in healthy young individuals. From the viewpoint of glucose regulation, it was suggested that it is important to eat breakfast even in healthy young individuals. Future studies should consider the chronic effects of breakfast skipping on glucose regulation and macronutrient composition of breakfast effects on glucose regulation.

\section{Acknowledgements}

We thank all the study investigators and staff and individuals who participated in the present study, especially Dr Kumpei Tokuyama.

The present study was supported by a Grand-in-Aid for Japan Society for the Promotion of Science (JSPS) Research Fellows (no. 17K179110A to H. O. and no. 18K17949 to Y. H.).

The authors' contributions are as follows: H. O., Y. H., E. Y. and H. T. designed the experiments. H. O. conducted the experiments, performed the data analysis and wrote the manuscript. Y. H., Y. G., E. T. and E. Y. conducted the experiments. Y. H., E. Y., K. Kiyono, Y. U., K. Kawanaka and N. O. edited the manuscript. All authors read and approved the final version of the manuscript.

The authors declare that there are no conflicts of interest.

\section{References}

1. Leidy HJ, Hoertel HA, Douglas SM, et al. (2015) A high-protein breakfast prevents body fat gain, through reductions in daily intake and hunger, in "breakfast skipping" adolescents. Obesity (Silver Spring) 23, 1761-1764.

2. Ferrer-Cascales R, Sánchez-SanSegundo M, Ruiz-Robledillo N, et al. (2018) Eat or skip breakfast? The important role of breakfast quality for health-related quality of life, stress and depression in Spanish adolescents. Int J Environ Res Public Health 15, E1781.

3. Spence C (2017) Breakfast: the most important meal of the day? Int J Gastron Food Sci 8, 1-6.

4. Smith KJ, Gall SL, McNaughton SA, et al. (2010) Skipping breakfast: longitudinal associations with cardiometabolic risk factors in the childhood determinants of adult health study. Am J Clin Nutr 92, 1316-1325.

5. Mekary RA, Giovannucci E, Willett WC, et al. (2012) Eating patterns and type 2 diabetes risk in men: breakfast omission, eating frequency, and snacking. Am J Clin Nutr 95, 1182-1189.

6. Ma Y, Bertone ER, Stanek EJ III, et al. (2003) Association between eating patterns and obesity in a free-living US adult population. Am J Epidemiol 158, 85-92.

7. Song WO, Chun OK, Obayashi S, et al. (2005) Is consumption of breakfast associated with body mass index in US adults? J Am Diet Assoc 105, 1373-1382.

8. Ballon A, Neuenschwander M \& Schlesinger S (2019) Breakfast skipping is associated with increased risk of type 2 diabetes among adults: a systematic review and meta-analysis of prospective cohort studies. J Nutr 149, 106-113.

9. Bi H, Gan Y, Yang C, et al. (2015) Breakfast skipping and the risk of type 2 diabetes: a meta-analysis of observational studies. Public Health Nutr 18, 3013-3019.

10. Haug E, Rasmussen M, Samdal O, et al. (2009) Overweight in school-aged children and its relationship with demographic and lifestyle factors: results from the WHO Collaborative Health Behaviour in School-aged Children (HBSC) study. Int J Public Health 54, 167-179.

11. Horikawa C, Kodama S, Yachi Y, et al. (2011) Skipping breakfast and prevalence of overweight and obesity in Asian and Pacific regions: a meta-analysis. Prev Med 53, 260-267.

12. Szajewska H \& Ruszczynski M (2010) Systematic review demonstrating that breakfast consumption influences body weight outcomes in children and adolescents in Europe. Crit Rev Food Sci Nutr 50, 113119.

13. Chatelan A, Castetbon K, Pasquier J, et al. (2018) Association between breakfast composition and abdominal obesity in the 
Swiss adult population eating breakfast regularly. Int J Behav Nutr Phys Act 15, 115.

14. Brown AW, Bohan Brown MM, Allison DB, et al. (2013) Belief beyond the evidence: using the proposed effect of breakfast on obesity to show 2 practices that distort scientific evidence. $A m J$ Clin Nutr 98, 1298-1308.

15. Betts JA, Richardson JD, Chowdhury EA, et al. (2014) The causal role of breakfast in energy balance and health: a randomized controlled trial in lean adults. Am JClin Nutr 100, 539-547.

16. Chowdhury EA, Richardson JD, Holman GD, et al. (2016) The causal role of breakfast in energy balance and health: a randomized controlled trial in obese adults. Am J Clin Nutr 103, 747-756.

17. Betts JA, Chowdhury EA, Gonzalez JT, et al. (2016) Is breakfast the most important meal of the day? Proc Nutr Soc 75, 464-474.

18. Ceriello A (2005) Postprandial hyperglycemia and diabetes complications: is it time to treat? Diabetes 54, 1-7.

19. Shichiri M, Kishikawa H, Ohkubo Y, et al. (2000) Long-term results of the Kumamoto Study on optimal diabetes control in type 2 diabetic patients. Diabetes Care 23, B21-B29.

20. Stratton IM, Adler AI, Neil HA, et al. (2000) Association of glycaemia with macrovascular and microvascular complications of type 2 diabetes (UKPDS 35): prospective observational study. BMJ 321, 405-412

21. Hu FB, Stampfer MJ, Solomon CG, et al. (2001) The impact of diabetes mellitus on mortality from all causes and coronary heart disease in women: 20 years of follow-up. Arch Intern Med 161, 1717-1723.

22. Monnier L, Colette $C \&$ Owens DR (2009) Integrating glycaemic variability in the glycaemic disorders of type 2 diabetes: a move towards a unified glucose tetrad concept. Diabetes Metab Res Rev 25, 393-402.

23. Cavalot F, Petrelli A, Traversa M, et al. (2006) Postprandial blood glucose is a stronger predictor of cardiovascular events than fasting blood glucose in type 2 diabetes mellitus, particularly in women: lessons from the San Luigi Gonzaga Diabetes Study. J Clin Endocrinol Metab 91, 813-819.

24. Siegelaar SE, Holleman F, Hoekstra JB, et al. (2010) Glucose variability: does it matter? Endocr Rev 31, 171-182.

25. Monnier L, Lapinski H \& Colette C (2003) Contributions of fasting and postprandial plasma glucose increments to the overall diurnal hyperglycemia of type 2 diabetic patients: variations with increasing levels of $\mathrm{HbA}(1 \mathrm{c})$. Diabetes Care 26, 881-885.

26. Ceriello A, Colagiuri S, Gerich J, et al. (2008) Guideline for management of postmeal glucose. Nutr Metab Cardiovasc Dis $\mathbf{1 8}$, S17-S33.

27. Kang X, Wang C, Lifang L, et al. (2013) Effects of different proportion of carbohydrate in breakfast on postprandial glucose excursion in normal glucose tolerance and impaired glucose regulation subjects. Diabetes Technol Ther 15, 569-574.

28. Pearce KL, Noakes M, Keogh J, et al. (2008) Effect of carbohydrate distribution on postprandial glucose peaks with the use of continuous glucose monitoring in type 2 diabetes. Am J Clin Nutr 87, 638-644.

29. Jovanovic A, Leverton E, Solanky B, et al. (2009) The secondmeal phenomenon is associated with enhanced muscle glycogen storage in humans. Clin Sci (Lond) 117, 119-127.

30. Jakubowicz D, Wainstein J, Ahren B, et al. (2015) Fasting until noon triggers increased postprandial hyperglycemia and impaired insulin response after lunch and dinner in individuals with type 2 diabetes: a randomized clinical trial. Diabetes Care 38, 1820-1826.

31. Kobayashi F, Ogata H, Omi N, et al. (2014) Effect of breakfast skipping on diurnal variation of energy metabolism and blood glucose. Obes Res Clin Pract 8, e249-e257.

32. Ogata H, Kayaba M, Tanaka Y, et al. (2019) Effect of skipping breakfast for six days on energy metabolism and diurnal rhythm of blood glucose in young healthy Japanese males. Am J Clin Nutr 110, 41-52.

33. World Health Organization (2019) Obesity and overweight. https://www.who.int/news-room/fact-sheets/detail/obesityand-overweight (accessed January 2019).

34. Chen T, Xu F, Su JB, et al. (2013) Glycemic variability in relation to oral disposition index in the subjects with different stages of glucose tolerance. Diabetol Metab Syndr 5, 38.

35. Ministry of Health, Labour and Welfare of Japan (2018) The National Health and Nutrition Survey 2015 [in Japanese]. http://www.mhlw.go.jp/file/04-Houdouhappyou-10904750Kenkoukyoku-Gantaisakukenkouzoushinka/0000041955.pdf (accessed May 2018).

36. Hatamoto Y, Goya R, Yamada Y, et al. (2017) Effect of exercise timing on elevated postprandial glucose levels. J Appl Physiol 123, 278-284.

37. Rodbard D (2016) Continuous glucose monitoring: a review of successes, challenges, and opportunities. Diabetes Technol Ther 18, 203-213.

38. Service FJ, Molnar GD, Rosevear JW, et al. (1970) Mean amplitude of glycemic excursions, a measure of diabetic instability. Diabetes 19, 644-655.

39. McDonnell CM, Donath SM, Vidmar SI, et al. (2005) A novel approach to continuous glucose analysis utilizing glycemic variation. Diabetes Technol Ther 7, 253-263.

40. Service FJ \& Nelson RL (1980) Characteristics of glycemic stability. Diabetes Care 3, 58-62.

41. Peng CK, Havlin S, Stanley HE, et al. (1995) Quantification of scaling exponents and crossover phenomena in nonstationary heartbeat time series. Chaos 5, 82-87.

42. Ogata H, Tokuyama K, Nagasaka S, et al. (2006) Long-range negative correlation of glucose dynamics in humans and its breakdown in diabetes mellitus. Am J Physiol Regul Integr Comp Physiol 291, R1638-R1643.

43. Ohkawara K, Oshima Y, Hikihara Y, et al. (2011) Real-time estimation of daily physical activity intensity by a triaxial accelerometer and a gravity-removal classification algorithm. BrJ Nutr 105, 1681-1691.

44. Bonuccelli S, Muscelli E, Gastaldelli A, et al. (2009) Improved tolerance to sequential glucose loading (Staub-Traugott effect): size and mechanisms. Am J Physiol Endocrinol Metab 297, E532-E537.

45. Wajngot A, Grill V, Efendić S, et al. (1982) The Staub-Traugott effect. Evidence for multifactorial regulation of a physiological function. Scand J Clin Lab Invest 42, 307-313.

46. Carey PE, Halliday J, Snaar JE, et al. (2003) Direct assessment of muscle glycogen storage after mixed meals in normal and type 2 diabetic subjects. Am J Physiol Endocrinol Metab 284, E688-E694.

47. Jovanovic A, Gerrard J \& Taylor R (2009) The second-meal phenomenon in type 2 diabetes. Diabetes Care 32, 1199-1201.

48. Nuttall FQ, Mooradian AD, Gannon MC, et al. (1984) Effect of protein ingestion on the glucose and insulin response to a standardized oral glucose load. Diabetes Care 7, 465-470.

49. Lee SH, Tura A, Mari A, et al. (2011) Potentiation of the earlyphase insulin response by a prior meal contributes to the second-meal phenomenon in type 2 diabetes. Am J Physiol Endocrinol Metab 301, E984-E990.

50. Chowdhury EA, Richardson JD, Tsintzas K, et al. (2015) Carbohydrate-rich breakfast attenuates glycaemic, insulinaemic and ghrelin response to ad libitum lunch relative to morning fasting in lean adults. Br J Nutr 114, 98-107.

51. Nilsson A, Ostman E, Preston T, et al. (2008) Effects of GI vs content of cereal fibre of the evening meal on glucose tolerance at a subsequent standardized breakfast. Eur J Clin Nutr $\mathbf{6 2}$, $712-720$. 
52. Rahat-Rozenbloom S, Fernandes J, Cheng J, et al. (2017) The acute effects of inulin and resistant starch on postprandial serum short-chain fatty acids and second-meal glycemic response in lean and overweight humans. Eur J Clin Nutr 71, 227-233.

53. Nilsson AC, Ostman EM, Granfeldt Y, et al. (2008) Effect of cereal test breakfasts differing in glycemic index and content of indigestible carbohydrates on daylong glucose tolerance in healthy subjects. Am J Clin Nutr 87, 645-654.

54. Brighenti F, Benini L, Del Rio D, et al. (2006) Colonic fermentation of indigestible carbohydrates contributes to the secondmeal effect. Am J Clin Nutr 83, 817-822.

55. Lunde MS, Hjellset VT, Holmboe-Ottesen G, et al. (2011) Variations in postprandial blood glucose responses and satiety after intake of three types of bread. J Nutr Metab 2011, 437587.

56. Jenkins DJ, Wolever TM, Nineham R, et al. (1980) Improved glucose tolerance four hours after taking guar with glucose. Diabetologia 19, 21-24.

57. Jenkins DJ, Wolever TM, Taylor RH, et al. (1982) Slow release dietary carbohydrate improves second meal tolerance. $A m \mathrm{~J}$ Clin Nutr 35, 1339-1346.

58. Liljeberg HG, Akerberg AK \& Björck IM (1999) Effect of the glycemic index and content of indigestible carbohydrates of cereal-based breakfast meals on glucose tolerance at lunch in healthy subjects. Am J Clin Nutr 69, 647-655.

59. Trinick TR, Laker MF, Johnston DG, et al. (1986) Effect of guar on second-meal glucose tolerance in normal man. Clin Sci (Lond) 71, 49-55.

60. Wolever TM, Jenkins DJ, Ocana AM, et al. (1988) Second-meal effect: low-glycemic-index foods eaten at dinner improve subsequent breakfast glycemic response. Am J Clin Nutr $\mathbf{4 8}$, 1041-1047.

61. Arai H, Mizuno A, Sakuma M, et al. (2007) Effects of a palatinose-based liquid diet (Inslow) on glycemic control and the second-meal effect in healthy men. Metabolism 56, 115-121.

62. Granfeldt Y, Wu X \& Björck I (2006) Determination of glycaemic index; some methodological aspects related to the analysis of carbohydrate load and characteristics of the previous evening meal. Eur J Clin Nutr 60, 104-112.

63. Liljeberg H \& Björck I (2000) Effects of a low-glycaemic index spaghetti meal on glucose tolerance and lipaemia at a subsequent meal in healthy subjects. Eur J Clin Nutr 54, 24-28.

64. Chen MJ, Jovanovic A \& Taylor R (2010) Utilizing the secondmeal effect in type 2 diabetes: practical use of a soya-yogurt snack. Diabetes Care 33, 2552-2254.

65. Meng H, Matthan NR, Ausman LM, et al. (2017) Effect of prior meal macronutrient composition on postprandial glycemic responses and glycemic index and glycemic load value determinations. Am J Clin Nutr 106, 1246-1256.

66. Park YM, Heden TD, Liu Y, et al. (2015) A high-protein breakfast induces greater insulin and glucose-dependent insulinotropic peptide responses to a subsequent lunch meal in individuals with type 2 diabetes. J Nutr 145, 452-458.

67. Ando T, Nakae S, Usui C, et al. (2018) Effect of diurnal variations in the carbohydrate and fat composition of meals on postprandial glycemic response in healthy adults: a novel insight for the second-meal phenomenon. Am J Clin Nutr 108, 332-342.

68. Wolever TM, Bentum-Williams A \& Jenkins DJ (1995) Physiological modulation of plasma free fatty acid concentrations by diet. Metabolic implications in nondiabetic subjects. Diabetes Care 18, 962-970.

69. Boden G (1998) Free fatty acids (FFA), a link between obesity and insulin resistance. Front Biosci 3, d169-d175.

70. Ferrannini E, Barrett EJ, Bevilacqua S, et al. (1983) Effect of fatty acids on glucose production and utilization in man.J Clin Invest 72, 1737-1747.

71. Rabinovitz HR, Boaz M, Ganz T, et al. (2014) Big breakfast rich in protein and fat improves glycemic control in type 2 diabetics. Obesity (Silver Spring) 22, E46-E54.

72. Monnier L, Colette C \& Boniface H (2006) Contribution of postprandial glucose to chronic hyperglycaemia: from the "glucose triad" to the trilogy of "sevens". Diabetes Metab 32, 2S11-2S16.

73. Anonymous (1999) Glucose tolerance and mortality: comparison of WHO and American Diabetes Association diagnostic criteria. The DECODE study group. European Diabetes Epidemiology Group. Diabetes Epidemiology: Collaborative analysis Of Diagnostic criteria in Europe. Lancet 354, 617-621.

74. Tominaga M, Eguchi H, Manaka H, et al. (1999) Impaired glucose tolerance is a risk factor for cardiovascular disease, but not impaired fasting glucose. The Funagata Diabetes Study. Diabetes Care 22, 920-924.

75. Chiasson JL, Josse RG, Gomis R, et al. (2003) Acarbose treatment and the risk of cardiovascular disease and hypertension in patients with impaired glucose tolerance: the STOPNIDDM trial. JAMA 290, 486-494.

76. Nakagami T; DECODA Study Group. (2004) Hyperglycaemia and mortality from all causes and from cardiovascular disease in five populations of Asian origin. Diabetologia 47, 385-394.

77. Nyaradi A, Li J, Foster JK, et al. (2016) Good-quality diet in the early years may have a positive effect on academic achievement. Acta Paediatr 105, e209-e218.

78. Burrows T, Goldman S, Pursey K, et al. (2017) Is there an association between dietary intake and academic achievement: a systematic review. J Hum Nutr Diet 30, 117-140. 